\title{
Institucionalização da gestão sustentável em instituições de ensino superior: um estudo com servidores da Universidade Federal do Tocantins
}

\section{Marcela Costa Campos ${ }^{1}$ e Lia de Azevedo Almeida ${ }^{2}$}

\author{
${ }^{1}$ Universidade Federal do Tocantins. Curso de Graduação em Administração. \\ ${ }^{2}$ Universidade Federal do Tocantins. Programa de Pós-Graduação em \\ Desenvolvimento Regional e Mestrado Profissional em Gestão de Políticas \\ Públicas.
}

Resumo. As Instituições de Ensino Superior (IES) têm um importante papel na gestão sustentável no desenvolvimento de suas atividades. Através das práticas e ações é possível constar que as mesmas podem contribuir para sociedade e meio ambiente, por meio do conhecimento científico, que normativamente são pautados por políticas e instrumentos de gestão socioambientais. Por esse motivo a pesquisa objetivou analisar a institucionalização da gestão sustentável na Universidade Federal do Tocantins, Brasil. Sendo classificada como tipo de pesquisa descritiva, com abordagem qualitativa e quantitativa, o estudo passou por três etapas metodológicas, pesquisa bibliográfica e documental e aplicação de questionário aos servidores da universidade. Como síntese de resultados relevantes, pode-se destacar que os servidores pouco conhecem sobre as práticas socioambientais, especialmente as voltadas para uso racional de água. A gestão sustentável da universidade apresenta muitos fatores limitadores quanto a atividades relacionadas à comunicação por parte da Comissão Socioambiental para com os servidores, bem como outras limitações para institucionalização das práticas, como falta de alinhamento ou o cumprimento das normativas dentro da universidade.

Palavras-chaves: Gestão sustentável; Administração pública; Instituições de Ensino Superior.

\begin{abstract}
Institutionalization of sustainable management in higher education institutions: A study with servers from the Federal University of Tocantins. Higher Education Institutions have an important role in sustainable management in the development of their activities. Through the practices and actions it can be stated that they can contribute to society and the environment, through scientific knowledge, which are normatively governed by socio-environmental management policies and instruments. For this reason the research aimed to analyze the institutionalization of sustainable management at the
\end{abstract}

Recebido

$22 / 10 / 2019$

Aceito

$23 / 12 / 2019$

Publicado

$31 / 12 / 2019$

Acesso aberto

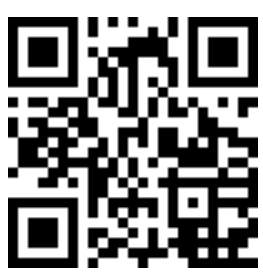

ORCID

(1) 0000-0001-5468-9147 Marcela Costa Campos

() 0000-0002-6586-4067

Lia de Azevedo

Almeida 
Federal University of Tocantins, Brazil. Being classified as a type of descriptive research, with a qualitative and quantitative approach, the study went through three stages methodologies, bibliographical and documentary research and application of questionnaire to university servers. As a synthesis of relevant results, it can be highlighted in the research axes of the applied questionnaire that the servers are not familiar with socioenvironmental practices, especially those focused on the rational use of water. The sustainable management of the university presents many limiting factors regarding activities related to communication by the Socio-Environmental Commission to the servers, as well as other limitations to institutionalization of the practices, such as lack of alignment or compliance with regulations within the university.

Keywords: Sustainable management; Public administration; Higher Education Institutions.

\section{Introdução}

Os problemas ambientais e sociais entraram em evidência na sociedade por volta do início do século XX e a relevância desses eventos influenciou sobre a atuação dos governos e organizações mundiais na busca por alternativas que procurassem minimizar os efeitos catastróficos evidentes no planeta.

Atualmente é possível notar, década após década, a redefinição do paradigma sustentável dentro do desenvolvimento, do processo de produção e do consumo. Nos dias atuais percebe-se que o uso desordenado dos recursos naturais para suprir as necessidades evolucionárias da sociedade tem sido posto em centralidade nos principais debates de organizações do mundo sobre o futuro da humanidade. A adoção do termo "desenvolvimento sustentável" que se propunha a afirmação de inúmeros acordos entre países, para alinhar estratégias de produção e consumo sustentável de forma a aumentar a expectativa das pessoas na terra, passou a ser definitivamente um lema obrigatório de inserção social na sociedade.

A evolução do termo sustentabilidade tomou grandes proporções nos últimos 30 anos, após muitas décadas ser considerado inconsistente, por defensores do desenvolvimento a qualquer custo. Ao saber, o conceito de desenvolvimento sustentável, foi utilizado pela primeira vez em 1987, após a Conferência de Nações Unidas sobre o Meio Ambiente, conhecido como a Rio'92 ou a mais importante reunião sobre meio ambiente e desenvolvimento (Biderman et al., 2008; Pinheiro, 2013).

Abrangentes noções de sustentabilidade, como leis, decretos, redefinições do termo, relatórios de sustentabilidade, têm sido enfatizadas todos os anos, por governos, com objetivo de influenciar uma nova cultura de responsabilidade nos setores da sociedade (Campagnin, 2014). As organizações, por exemplo, tem sido alvo de diferentes ações governamentais no sentido de proverem de mecanismos que almejem o equilíbrio social e ambiental no âmbito da comunidade que atuam. Para Cogo et al. (2012), a sustentabilidade é uma necessidade que busca garantir recursos naturais para todos, por meio de uma gestão eficiente das organizações, com ampla proteção ambiental e desenvolvimento econômico equilibrado.

No setor público é imprescindível destacar o papel que o governo desempenha para promover mudanças no paradigma sustentável, por meio de diretrizes e modelos estratégicos. Muitas 
ferramentas como, a agenda ambiental, compras públicas sustentáveis, plano de logística sustentável foram desenvolvidas neste setor, com objetivo de assegurar a aplicabilidade da gestão socioambiental dos órgãos públicos brasileiros.

No âmbito público é importante frisar que as IES's (Instituições de Ensino Superior) têm um importante ofício no desenvolvimento de repostas e soluções para problemas relacionados ao meio ambiente e sociedade (Viegas e Cabral, 2015). As mesmas contribuem com o ensino, a conscientização, a pesquisa e a prática, que vão desde a responsabilidade institucional ao desenvolvimento de alternativas para a comunidade associada.

Com a presente apresentação, a pesquisa objetivou analisar a institucionalização da gestão sustentável na Universidade Federal do Tocantins. Para isso necessitou avaliar outras variáveis como a caracterização dos instrumentos de gestão sustentável da Universidade, a percepção dos servidores quanto à institucionalização da gestão sustentável e as deficiências apontadas quando à gestão socioambiental da universidade. Para alcance dos objetivos, propôs-se em analisar a percepção dos servidores que trabalham em departamentos de chefias, como diretorias, coordenações e próreitorias sobre a presença da gestão sustentável na instituição, através da aplicação de um questionário adaptado de Rek (2017) e Lima (2018). Ademais, acrescentou-se a necessidade de fazer uma análise documental de relatórios, leis e principalmente do PGLS da Universidade Federal do Tocantins. 0 PGLS da Universidade Federal do Tocantins, tido como um dos objetos de estudo dessa pesquisa, foi elaborado pela primeira vez em 2013 e tinha como ideia, a implementação de um novo modelo de cultura, voltado para Universidade com objetivo de inserir propostas de elaboração, acompanhamento e controle de ações de finalidade ambiental, social e econômica para comunidade interna e externa da instituição.

Justifica-se a pesquisa sobre a relevância da atuação de uma Instituição de Ensino Superior sobre a gestão sustentável. É importante ressaltar que as Instituições de Ensino Superior têm uma importante função no estímulo de ações para com a gestão social e ambiental na sociedade. Viegas e Cabral (2015) consideram que as Instituições de Ensino Superior, sejam elas públicas ou privadas, tem papel social e política na qual podem ser desenvolvidas atividades, responsáveis pela construção de um conhecimento científico, voltado para organizações, sociedade e meio ambiente. Para Almeida (2015) a atuação da IES é uma alternativa que traz prerrogativas e novas formas de agir, trazendo benefícios para o meio ambiente e sociedade, reduzindo os efeitos negativos, por meio de ações ecologicamente corretas para auxiliar na condição de vida adequada para cidadãos à sua volta. Adicionalmente, este estudo colabora com a gestão da própria universidade, dando continuidade há alguns estudos já realizados como o de Silva e Almeida (2019b), que analisaram indicadores de sustentabilidade no campus de Araguaína da Universidade Federal do Tocantins, que indentificou que há práticas sustentáveis em pelo menos $\quad 43,3 \%$ dos indicadores pesquisados.

\section{Referencial teórico}

\section{0 contexto da crise socioambiental: 0 despertar da sustentabilidade}

A produção e os padrões de consumo da população mundial chegaram a níveis alarmantes nos últimos 50 anos. À medida que a sociedade evolui, eleva-se também a necessidade de recursos e por seguinte a compensação de matéria retirada da natureza para ser utilizada na produção de produtos para atender a demanda. 
Nascimento (2012, p. 58), nessa perspectiva completa que "caso continuemos no ritmo de crescimento econômico dos últimos cem anos, teremos cerca de 120 milhões de pessoas por ano adentrando o mercado de consumo. Serão mais dois bilhões e meio em 2050". O problema torna-se um limite no modo de vida que as pessoas vêm tendo há alguns anos, uma vez que os recursos e insumos que o mercado consumidor necessita, passam pela realidade do limite e esgotamento.

É possível notar que a preocupação com o esgotamento de recursos na esfera do consumo e produção não surgiu recentemente. De acordo com Tigre (2006) o problema começou a ser notado no início do século $\mathrm{XX}$, quando inúmeras industriais de altíssimo desempenho começaram a ser incorporadas nos meios de produção de produtos, guiados pelo avanço tecnológico, novos modelos de produtividade e eficiência. De acordo com Galvão (2014), as indústrias sempre foi e sempre serão os grandes agentes econômicos que norteiam as enormes manifestações do processo social econômico, contudo, atualmente apresentam características da contemporaneidade e desenvolvimento. Elas têm limitado os antigos paradoxos e sobrecarga sobre os recursos naturais, por meio de uma nova cultura e modo de vida capitalista socialmente responsável.

Ainda sobre a crise ambiental que se instaurava no mundo por volta do início do século XX, Martins (2015, p. 2) destaca que aconteceu, em quase sua totalidade, "por conta do empenho de especialistas das ciências naturais em insistir nos problemas ecológicos que o crescimento populacional trazia às sociedades industriais no início do século XX". A predominante preocupação que iniciou nesse período fez com que muitas políticas voltadas para empresas de produção, mudassem suas visões para com um novas alternativas produtivas.

Viegas e Cabral (2015) também fazem algumas considerações sobre 0 contexto da crise socioambiental no contexto das empresas públicas e privadas. Os autores explicam que o olhar mais centrado para problemas ambientais dessa época influenciou muito para que a sustentabilidade fosse introduzida nas agendas políticas de empresas do setor público e privado. Ressalta-se nesta perspectiva, que muitos provimentos legais foram admitidos por novas políticas, tratados e acordos internacionais, dentro de empresas e instituições públicas, nas quais incluía a reutilização de resíduos sólidos, reciclagem, energia limpa e tratamento de dejetos. Viegas e Cabral (2015) definem essas ações, como indicadores da chamada "sustentabilidade organizacional".

Na extensa caminhada evolutiva do contexto de crise ambiental e consequentemente a social, a sustentabilidade organizacional veio ganhando notoriedade ano após ano. A discussão mais arrojada "iniciada em meados dos anos 1970 foi aos poucos ganhando repercussão e, atualmente é motivo de preocupação global (Lopes e Pacagnan, 2015 , p. 1). A sensibilidade na qual foi incluído os problemas relacionados ao meio ambiente e a crise social, atravessam os vértices de estudos internacionais que apontavam o caos em volta desses eixos, e que consequentemente podem trazer imensuráveis conflitos em todo globo. Desse momento pode-se observar uma nova temática surgindo sobre a questão socioambiental, na qual se apresentava a sustentabilidade.

A sustentabilidade socioambiental está associada ao desenvolvimento, e esse termo surgiu na economia, logo após a Segunda Guerra Mundial, quando "os economistas neoclássicos definiram o desenvolvimento como crescimento econômico e traçaram como objetivo principal a maximização do Produto Interno Bruto (PIB)" (Garcia et al., 2007, p. 1). Os autores continuam afirmando que na década de 1980 o contexto da crise do desenvolvimento era pautado 
pela crítica ecologista, na qual exigia uma reflexão mais complexa do conceito.

Benites e Polo (2013) faz uma excelente conceituação do termo sustentabilidade ao afirmar ser um guia que orienta empresas no mundo econômico, com novas maneiras de gerenciar, com maior eficiência e produtiva, em constante relação com meio ambiental, o social e o financeiro, guiado pelo desenvolvimento e abertura de novos negócios. 0 termo sustentabilidade é um complexo de estudos que vislumbram vários setores da sociedade, contudo, de uma forma mais abrangente tem basicamente duas origens, de acordo com Nascimento (2012), uma na Biologia e outra na Economia.

0 ambientalismo, fundamentado na perspectiva ecológica e econômica, são complexidades que norteiam as possibilidades relacionais entre essas duas grandes áreas, com a finalidade de encontrar saídas para solucionar problemas advindos da superprodução de consumo da sociedade. E é nesse contexto, entre ecologia e econômica que se fundamenta o ambientalismo empresarial e responsabilidade socioambiental. De acordo com Lopes e Pacagnan (2014) esses dois fundamentos supracitados tiveram explosão na década de 1990, justamente pela força e atuação de comunidades ambientalistas que lutavam pelo desenvolvimento, mas com sustentabilidade (ecológico e econômico).

As empresas e instituições que aderem à sustentabilidade socioambiental ganham visibilidade, viram sinônimo de organizações sustentáveis e ganham reconhecimento no mercado. Em empresas privadas as escolhas e estratégias voltadas para o social e ambiental são naturalmente práticas associadas a gestão estratégia da empresa (Scherer, 2009). Nas organizações públicas, são vistas como instituições de excelência, reconhecida pela sociedade e governo e que naturalmente reduzirem os custos assistenciais abusivos dos cofres públicos.

Sustentabilidade para empresas e para sociedade é um mecanismo de transformação que agrega valor e desenvolvimento de forma continuada de componentes e alternativas sustentáveis que melhoram a qualidade de vida das pessoas e ajudam o meio ambiente. Cada um desses componentes e alternativas são influenciadores da sustentabilidade social, ambiental e econômica.

No mundo corporativo, Souza et al. (2017) destacam em seus estudos que existem na sustentabilidade, três eixos (um tripé) no qual devem ser desenvolvidos: (i) sustentabilidade ambiental; (ii) sustentabilidade social e; (iii) sustentabilidade econômica. Em uma conceituação mais simplificada, Elkington (1999) afirma que o primeiro eixo diz respeito à gestão e eficiência na utilização de recursos naturais e ambientais. 0 segundo diz respeito as ações que geram valor e tem sentido para pessoas dentro e fora das organizações. E o terceiro, refere-se às ações que em comum similaridade, com ambiental e social geram rentabilidade para empresa.

Para Quintanda et al. (2012, p. 2), o tripé da sustentabilidade "consiste em buscar um equilíbrio sistêmico entre o governo, empresas e a sociedade, pois todos fazem parte do ecossistema que trata das relações dos organismos entre si, e com o meio ambiente". Dessa forma, é natural que a degradação ambiental e o enfretamento de problemas sociais sejam de responsabilidade de todas as partes supracitadas, uma vez que o desenvolvimento econômico seja pautado também pelo desenvolvimento sustentável. Para isso, setores e organismos (governo, empresas e pessoas) que compõe a sociedade, criaram algumas das principais diretrizes para sustentabilidade (Tabela 1), sustentada por grandes organizações e ferramentas de gestão (Galvão, 2014). 
Tabela 1. Princípios e diretrizes para a sustentabilidade.

\begin{tabular}{|c|c|c|}
\hline Origem/Abrangência & $\begin{array}{c}\text { Ferramenta de } \\
\text { Gestão }\end{array}$ & Descrição \\
\hline $\begin{array}{l}\text { Organização para Cooperação e } \\
\text { Desenvolvimento Econômico - } \\
\text { OCDE/abrangência } \\
\text { internacional }\end{array}$ & $\begin{array}{l}\text { Diretrizes para } \\
\text { Empresas } \\
\text { Multinacionais }\end{array}$ & $\begin{array}{llll}\text { Diretrizes orientadoras para } & \text { padrões } \\
\text { voluntários em termos de } & \text { ampla } & \text { conduta } \\
\text { ética social e ambiental } & & \end{array}$ \\
\hline $\begin{array}{l}\text { Programa das Nações Unidas } \\
\text { para o Desenvolvimento - } \\
\text { PNUD/abrangência } \\
\text { internacional }\end{array}$ & Pacto Global & $\begin{array}{l}\text { Estabelece dez princípios voluntários para os } \\
\text { direitos humanos, do trabalho, da proteção } \\
\text { ambiental e contra a corrupção. }\end{array}$ \\
\hline $\begin{array}{l}\text { Programa das Nações Unidas } \\
\text { para o Desenvolvimento - } \\
\text { PNUD/abrangência } \\
\text { internacional }\end{array}$ & $\begin{array}{l}\text { Metas do } \\
\text { Milênio }\end{array}$ & $\begin{array}{l}\text { Define oito objetivos internacionais comuns } \\
\text { para o desenvolvimento do milênio e fixa } 18 \\
\text { metas e } 48 \text { indicadores que devem ser } \\
\text { adotados pelos países membros da ONU. }\end{array}$ \\
\hline $\begin{array}{l}\text { Programa das Nações Unidas } \\
\text { para o Desenvolvimento - } \\
\text { PNUD/abrangência } \\
\text { internacional }\end{array}$ & Carta da Terra & $\begin{array}{l}\text { Documento que trata do amplo discurso } \\
\text { ecológico e social estruturado em } 4 \text { princípios } \\
\text { e } 16 \text { proposições para o desenvolvimento } \\
\text { sustentável }\end{array}$ \\
\hline $\begin{array}{l}\text { Programa das Nações Unidas } \\
\text { para o Desenvolvimento - } \\
\text { PNUD/abrangência } \\
\text { internacional }\end{array}$ & Agenda 21 & $\begin{array}{l}\text { Traduz em ações o conceito do } \\
\text { desenvolvimento sustentável, dividido em } 4 \\
\text { seções e } 40 \text { capítulos. }\end{array}$ \\
\hline $\begin{array}{l}\text { International } r \text { Finance } \\
\text { Corporation - IFC/abrangência } \\
\text { internacional }\end{array}$ & $\begin{array}{l}\text { Princípios do } \\
\text { Equador }\end{array}$ & $\begin{array}{l}\text { Estabelece procedimentos para concessão de } \\
\text { crédito assegurando que projetos financiados } \\
\text { sejam desenvolvidos de forma socialmente e } \\
\text { ambientalmente responsável }\end{array}$ \\
\hline
\end{tabular}

Fonte: Galvão (2014), adaptado de Louette (2007).

Os documentos, conferências, relatórios e procedimentos, estabelecem princípios básicos para a elevação expressiva, em torno do tema sustentabilidade. Neles são debatidos sobre questões sociais e ambientais, elencadas por discernimentos dos direitos humanos de se viver bem e com dignidade.

\section{A gestão socioambiental}

o conceito de gestão socioambiental refere-se em suma na ação de se discutir e buscar por alternativas, com o objetivo de resolver problemas ambientais, tendo como foco a responsabilidade social (Berté, 2009). Para Donaire (2010) a responsabilidade é tida com um aglomerado de atividades onde empresas exercem de forma contínua, com a finalidade de prover de melhorias ambientais e qualidade de vida para pessoas, assim como o alcance de recursos financeiros. Em uma definição mais absoluta do termo, Cavalcante (2012) destaca:

A responsabilidade socioambiental é um processo contínuo e progressivo de desenvolvimento de competências cidadãs, com a assunção de responsabilidades sobre questões sociais e ambientais relacionadas a todos os públicos com os quais a entidade interage: trabalhadores, consumidores, governo, empresas, investidores e acionistas, organizações da sociedade civil, mercado e concorrentes, comunidade e o próprio meio ambiente (Cavalcante, 2012, p. 9).

As empresas que aderem a responsabilidade socioambiental, ou seja, são responsáveis socialmente, garantem estratégias de desenvolvimento de mão dupla, que agem de forma consciente 
para si e para sociedade. Essas empresas "desempenham um papel proativo, implementando mudanças conceituais em seus procedimentos e agindo de forma consciente, sozinhas ou em parceria com ONGs ou governo" (Volpon e Macedo-Soares, 2007, p. 3).

Atualmente, dentro da gestão socioambiental, "o grande desafio para as instituições é encontrar ações que englobem o desenvolvimento no tripé da sustentabilidade social, ambiental e econômica" (Warken et al., 2014, p. 2). Para isso, é importante a conscientização de todos os agentes sociais na busca por alternativas em conjunto, a fim de manter a harmonização das determinações e processos que surjam, para focar em práticas de sustentabilidade dentro e fora das organizações.

Os modelos de gestão socioambientais adotados nos dias de hoje compreendem a solução de vários problemas, que naturalmente contribuem para o desenvolvimento sustentável através da produção limpa. Essas atribuições contribuem para a formalização da responsabilidade das empresas. Ademais, essas "organizações precisam estar atentas não só às suas responsabilidades econômicas e legais, mas, também, às suas responsabilidades éticas, morais e sociais" (Bisognin Soares et al., 2014, p. 3). Os autores continuam frisando que a discussão em torno da atuação "social das empresas e da construção de uma ética empresarial acabou tendo consequências concretas, pois muitas empresas começaram a investir em áreas sociais, tradicionalmente ocupadas somente pelo governo" (Bisognin Soares et al., 2014, p. 10).

De acordo com Cavalcante (2012), a responsabilidade socioambiental tem amplitude de níveis global, porém é um pouco diferente para governos e empresas privadas, pois depende muito da influência econômica, social e ambiental, bem como as divergências sobre as necessidades nos parâmetros internacionais de cada país. Dessa forma é importante destacar que cada país e governo figuram-se em diferentes formas de regularizar e padronizar atividades e ações para com a responsabilidade socioambiental.

$\mathrm{Na}$ atualidade, as empresas garantem mais lucro quando associam a competitividade e concorrência para com estratégias ambientais e sociais. Essa atitude permite que atraiam mais clientes e vantagem para conquista de visibilidade. Nos dias de hoje os dois modelos de estratégias são apenas um, unificados pelo bem empresarial e sustentável. Para Quintanda et al. (2012, p. 2) "no que se refere às estratégias empresariais não é apenas visar o retorno econômico e sim um aprofundamento das questões socioambientais dentro da organização como garantia de permanecer no mercado. Da mesma forma escreve Galvão (2014, p. 39) que "a empresa economicamente sustentável seria aquela que consegue garantir, a qualquer tempo, fluxo de caixa suficiente para assegurar a liquidez ao produzir um retorno acima da média para seus acionistas".

As influências e relações positivas de valor nas organizações são fortemente aplicadas, por meio de um instrumento de gestão socioambiental, bem como instrumentos econômicos. Para Martins (2015, p. 5), “o valor sinalizado por instrumentos econômicos de gestão emerge como uma unidade de mensuração dos prejuízos ambientais e do nível de escassez dos recursos naturais". Isso faz com que as organizações assimilem os conflitos entre lucro, competividade e responsabilidade. Atualmente esses instrumentos são de referência no mundo organizacional, especialmente os criados dentro da administração pública, uma vez que servem como modelo para empresas privadas. 0 tópico a seguir tratará mais sobre instrumentos de gestão socioambiental na gestão pública. 


\section{Instrumentos de gestão socioambiental na gestão pública \\ Os órgãos públicos são} responsáveis pelo planejamento e organização de ações desenvolvidas para população e empresas, por meio de projetos, programas, leis e ferramentas (Huller, 2010). Esses tópicos são repassados a entes da sociedade civil justamente para dar continuidade e ideal de sustentabilidade, logo que elas sejam aplicadas em suas casas e empresas. 0 enfoque da questão socioambiental está na gestão pública em determinação do âmbito jurídico, mais especificamente na Lei $\mathrm{n}^{\circ}$ 6.938/1981, no seu art. 5ㅜㅜ, que dispõe sobre a Política Nacional do Meio Ambiente, seus fins e mecanismos de formulação e aplicação da legalidade no setor público (Brasil, 1981). Os compêndios que se referem às ferramentas, indicadores, normas e certificações para empresas, organizações públicas e governos partem da conscientização e responsabilidade: "o desenvolvimento sustentável e a responsabilidade socioambiental são conceitos que desdobram métodos e técnicas objetivos e concretos para se projetar uma efetivação da tutela socioambiental" (Venturi, 2015, p. 7).

De acordo com Huller (2010, p. 7) "os órgãos públicos, assim como as empresas e demais instituições possuem grandes fontes de geração de resíduos, que na maioria das vezes não são nem percebidos pelos seus gestores". Esse fato mostra que o consumo é fortemente atrelado pelo setor, e que naturalmente tem fortes influencias sobre o meio ambiente e problemas sociais. Por isso Carvalho e Souza (2013) recomendam que o estado seja sempre detentor de práticas e políticas públicas voltadas para regulação e formalização de suas ações para com suas atividades, por meio de instrumentos de gestão ambiental. Alguns instrumentos de gestão socioambiental na gestão pública são mostrados na Tabela 2 .

Tabela 2. Instrumentos de gestão socioambiental na gestão pública.

\begin{tabular}{|c|c|c|}
\hline Instrumento & Especificação & Autor \\
\hline $\begin{array}{c}\text { Programa } \\
\text { Agenda } \\
\text { Ambiental da } \\
\text { Administração } \\
\text { pública (A3P) }\end{array}$ & $\begin{array}{l}\text { A A3P é um programa que busca incorporar os princípios da } \\
\text { responsabilidade socioambiental nas atividades da Administração } \\
\text { Pública, através do estímulo a determinadas ações que vão, desde } \\
\text { uma mudança nos investimentos, compras e contratações de } \\
\text { serviços pelo governo, passando pela sensibilização e capacitação } \\
\text { dos servidores, pela gestão adequada dos recursos naturais } \\
\text { utilizados e resíduos gerados, até a promoção da melhoria da } \\
\text { qualidade de vida no ambiente de trabalho. }\end{array}$ & $\begin{array}{c}\text { Cavalcante } \\
\text { (2012) }\end{array}$ \\
\hline $\begin{array}{c}\text { Plano de } \\
\text { Logística } \\
\text { Sustentável - } \\
\text { PLS }\end{array}$ & $\begin{array}{l}\text { PLS é instrumento vinculado ao plano estratégico, com objetivos e } \\
\text { responsabilidades definidas, ações, metas, prazos de execução, } \\
\text { mecanismos de monitoramento e avaliação de resultados, que } \\
\text { permite estabelecer e acompanhar práticas de sustentabilidade, } \\
\text { racionalização e qualidade que objetivem uma melhor eficiência } \\
\text { do gasto público e da gestão dos processos de trabalho, } \\
\text { considerando a visão sistêmica do órgão }\end{array}$ & $\begin{array}{c}\text { Brasil } \\
(2015)\end{array}$ \\
\hline $\begin{array}{l}\text { Contratações } \\
\text { públicas } \\
\text { sustentáveis }\end{array}$ & $\begin{array}{c}\text { As contratações sustentáveis compreendem o uso } \\
\text { adequado de materiais licitados, por meio de requisitos } \\
\text { sustentáveis. São vislumbrados nesses aspectos, produtos de } \\
\text { empresas que prezam pelas especificações ambientais em todos os } \\
\text { processos de aquisição. O modelo fortalece a aplicação de } \\
\text { empresas sustentáveis e reforça o entorno sobre a questão } \\
\text { ambiental. }\end{array}$ & $\begin{array}{l}\text { Sousa et al. } \\
\text { (2014) }\end{array}$ \\
\hline
\end{tabular}


A especificidade de atuação do poder público na gestão socioambiental é um aspecto que abrange tanto sobre a referência de verificação e regularização nos grupos empresariais, bem como as ações municipais e órgão públicos nos âmbitos municipais, estaduais e federais. Geralmente existe nesse empasse, uma questão de difícil similaridade, pois, "as decisões concernentes à gestão ambiental, em geral, são efetivadas em um ambiente de intenso conflito de interesses, condicionando o grau de eficiência e de eficácia da política ambiental" (Cabral e Gomes, 2013, p. 5). Nesse sentido, cabe também ao poder público a resolução desses conflitos, para que dessa forma a gestão possa ser feita de forma ágil e eficiente.

\section{A sustentabilidade nas Institui- ções de Ensino Superior}

As Instituições de Ensino

Superior podem trazer grandes debates, ações e benefícios para com a responsabilidade social e ambiental na sociedade. Através de projetos educativos e gestão descentralizada, as IES podem acionar programas de ensino no sentido amplo de ações socioambientais. As práticas da instituições de ensino superior promovem a criação de novos programas e auxiliam a promoção de ações para com todos os modelos organizacionais e em todos os setores da sociedade. Para Viegas e Cabral (2015) essa afirmação é um complemento de que as práticas, atividades e ações desenvolvidas dentro da universidade podem ser altamente engrandecidas dentro da complicada relação entre homem e natureza.

Sousa et al. (2014) afirmam que as universidades causam grande degradação ambiental, uma vez que suas atividades acionam grandes impactos em seus espaços geográficos, o que reforça a tangibilidade de aplicar e desenvolver medidas que resolvam esses problemas de forma integralizada em torno dos agentes causadores. Essas medidas são relacionadas ao equilíbrio entre o campo teórico e a prática, com a finalidade de tornar o meio ambiente mais adequado ao mesmo tempo que se estabelece atividades universitárias (Almeida, 2015).

Está previsto no Plano Nacional de Educação de 2014 que a Instituições de Ensino Superior colaborem com soluções e criação de alternativas de problemas da sociedade, com a finalidade de contemplar de forma abrangente e de caráter humanitário, um cenário de qualidade de vida para as pessoas (Brasil, 2014). Dessa forma, as Instituições devem, por meio do conhecimento, dos alunos, dos professores, da gestão e da comunidade, buscar mecanismos que corroborem sobre as boas práticas socioambientais, no sentido de serem praticadas dentro da sociedade, com o objetivo de prover princípios adequados para os problemas sociais (Almeida, 2015).

A evolução e passo das universidades foram agregados ano após ano, especialmente por volta dos anos 80 e 90 quando a nível mundial, essas organizações trabalharam em ampla colaboração em prol da sustentabilidade através de pesquisas científicas e práticas (Viegas e Cabral, 2015). Tudo aconteceu após a Organização das Nações Unidas, em 1987 quando colocou o tema de sustentabilidade, dentro dos mais importantes debates sobre as atividades de empresas e órgãos públicos e suas influencias para com os efeitos negativos ao meio ambiente (Warken et al., 2014).

As IES são os principais pontos do direcionamento de diretrizes do Governo para desenvolvimento de ferramentas para questões socioambientais (Almeida, 2015). Dessa forma é interessante frisar que as mesmas asseguram uma gestão universitária mais eficiente com a criação de novas ferramentas de apoio.

É relevante destacar que todas as IES tem a função, enquanto sistema educacional de adequar suas atividades 
acadêmicas com princípios voltados para sustentabilidade, uma vez que tem como proposta principal, a construção de uma sociedade mais justa, com aspectos de instrução para compensação sustentável (Macedo et al., 2013). Neste sentido, Silva e Almeida (2019a, p. 136) ressaltam que "[...] as Universidades devem entender a sustentabilidade para além de fatores ambientais, ou apenas sociais, é importante que se observe as dimensões, como uma intersecção entre elas".

A Universidade Federal do Tocantins (UFT): o PGLS e a Comissão Socioambiental. A Universidade Federal do Tocantins, foi instituída em 23 de outubro de 2000, por meio da Lei $\mathrm{n}^{\mathrm{o}}$ 10.032/2000 (Brasil, 2000), sendo um Instituição de Ensino Superior pública, na qual promove o ensino, pesquisa e extensão no Estado do Tocantins, sendo um Instituição devidamente vinculada ao Ministério da Educação e caracterizada como didático-científica (UFT, 2018).

A Universidade Federal do Tocantins possui atualmente um quadro de 1096 docentes, e 863 técnicos administrativos (UFT, 2018). Além do câmpus de Palmas, a instituição possui ainda mais seis câmpus, espalhados estrategicamente pelo Estado. São eles, os campos de Tocantinópolis, Araguaína, Miracema, Porto Nacional, Gurupi e Arraias (UFT, 2018).

A universidade oferece cursos de graduação (bacharelados e tecnológicos), na modalidade EAD e presencial, pósgraduação, mestrado e doutorado. A sede da Instituição fica na capital do Estado, Palmas, onde também fica localizada a Reitoria da Universidade. A estrutura da gestão universitária segue um modelo de organograma vertical, onde são hierarquizados os setores e conselhos pertinentes a administração

O Consuni é o órgão deliberativo supremo, como maior representatividade acadêmica, e que por superioridade, traçam os objetivos, as metas, modelos de gestão e deliberações de formas democráticas, por votação e amplo debate sobre os rumos da gestão universitária. 0 Consuni também é responsável pela criação da Comissão Gestora do PGLS (Plano de Gestão de Logística Sustentável) da Universidade Federal do Tocantins, na qual planeja, executa e monitora ações de caráter socioambiental da Instituição.

De acordo com Almeida (2015), o Plano de Gestão de Logística Sustentável (PGLS) foi formalizado pela Instrução Normativa no 10/2012, da Secretária de Logística e Tecnologia da Informação, do Ministério do Planejamento, Orçamento e Gestão (Brasi, 2012). 0 objetivo do PGLS é construir a ideia da prática sustentável dentro da gestão universitária, por meio de ações sustentáveis, tornando mais adequada e justa o envolvimento da comunidade interna e os benefícios também para a comunidade externa da Universidade.

0 PGLS da UFT foi criado através da Portaria no 1.541, de 26 de agosto de 2013, onde teve sua primeira Comissão Gestora, formada por sete membros, dentro os quais eram servidores da Universidade distribuídos em três departamentos: Pró-Reitorias de Planejamento; Administração e Finanças; e Prefeitura Universitária (UFT, 2013).

0 último PGLS da UFT foi atualizado, por meio da Resolução no 6, de 14 de março de 2018, e a Comissão socioambiental é formada por dezessete membros, com maior inclusão e diversificação de setores de representação, das quais contam o DSMA/Reitoria, PROGRAD, PROEX, Campus de Tocantinópolis, PROPESQ, Prefeitura da UFT, Campus de Gurupi, Campus de Araguaína, Campus de Miracema, PROEST, Campus de Palmas, Campus de Arraias, PROAP, PROAD, Campus de Porto Nacional, PROGEDEP e DSMA/ Reitoria. A resolução recomenda à Comissão o apoio ao objetivo geral do PGLS, na qual inclui "Promover planos, projetos e ações que possibilitem a implantação de um novo modelo de cultura institucional que vise à inserção de critérios de sustentabilidade e 
economicidade nas atividades da administração pública, buscando desenvolver métodos novos que adotem os 5R's da Agenda A3P, no âmbito da Universidade Federal do Tocantins (UFT, 2018).

O PGLS da UFT é guiado para desenvolvimento sustentável, especificamente por quatro dimensões de sustentabilidade. São eles os eixos: Ambiental, Cultural, Econômico e Social. O PGLS da UFT busca melhorar o quesito socioambiental, por meio de ações que englobem 3 eixos: Gestão energética eficiente, Gestão da arquitetura da paisagem e Gestão de saneamento ambiental (UFT, 2018). Cada eixo é avaliado em objetivos específicos de planejamento e que buscam serem executados de imediato, curto, médio e logo prazo, além das ações com execução contínua. Em questões econômicas, no curto (até 2 anos), médio ( 2 a 4 anos) e longo prazo (5 a 8 anos), o objetivo é reduzir ao menos $\mathrm{R} \$ 2.000 .000,00 \mathrm{em}$ custos nos setes campus.

\section{Metodologia}

0 presente estudo assenta-se como um tipo de pesquisa descritiva, com abordagens qualitativa e quantitativa. Apresenta-se ainda a pesquisa, como um estudo de caso, com utilização de procedimentos técnicos, documental e bibliográfico. A coleta de dados da pesquisa iniciou na pesquisa documental, onde além de resoluções e leis, buscou informações relevantes no PGLS (Plano de Gestão de Logística Sustentável) da Universidade Federal do Tocantins. O objetivo dessa etapa de pesquisa foi analisar as práticas e metas do plano dentro da Universidade, assim como propostas de implementação para do plano. A pesquisa documental também buscou analisar os possíveis resultados da implementação, por meio de relatórios da instituição. A pesquisa analisou os últimos documentos e normativas do PGLS da universidade
Federal do Tocantins, que compreende período entre 2017 e 2018.

A outra etapa da pesquisa consistiu na aplicação de questionário para servidores da Universidade que trabalham em departamentos de chefias, como diretorias, coordenações e próreitorias. A Universidade Federal do Tocantins tem 1096 docentes e 863 técnicos administrativos em sete campi. Os participantes da pesquisa, contudo, foram apenas do campus Palmas, que tem quadro de 463 docentes e 191 técnicos administrativos. Os pesquisados do campus foram selecionados por acessibilidade, ou seja, aqueles que se disponibilizaram responder 0 questionário. Dessa forma, a amostra da pesquisa pode ser caracterizada como não probabilística. Cerca de 150 questionários foram entregues nos departamentos da Universidade e outros enviados por e-mail, contudo, a taxa de retorno de 31 questionários válidos.

0 roteiro é uma adaptação do questionário de Rek (2017) e Lima (2018) onde fizeram trabalhos com avaliação semelhante no Tribunal Regional Eleitoral do Paraná e Tribunal de Justiça do Tocantins, respectivamente. 0 questionário possui 25 questões, nas quais foram divididas da seguinte forma: três questões sobre conhecimento da temática e legislação ambiental; uma questão sobre a comissão socioambiental e sua relação com a instituição; duas questões sobre a questão socioambiental e a institucionalização na Universidade Federal do Tocantins; cinco questões sobre a sensibilização e capacitação socioambiental na Universidade Federal do Tocantins; e 13 questões sobre as práticas socioambientais.

Os procedimentos para análise dos dados do presente estudo aconteceram em três passos, como propostos nos estudos de Carvalho e Vergara (2002): (i) agrupar as informações e depoimentos, (ii) reunir em formações maiores e (iii) discutir e analisar os dados. A análise de dados tem 
a função de organizar e entendê-los de tal forma que possibilite o entendimento das respostas ao problema da pesquisa. A interpretação teve como objetivo procurar o sentido mais abrangente das respostas, através de uma análise mais sistemática do pesquisador e a especificação tenciona verificar até quando as variáveis são válidas.

\section{Resultados e discussão}

\section{Conhecimento da temática e legislação ambiental}

Essa etapa de análise de dados, busca mostrar os resultados pertinentes ao conhecimento dos servidores, quanto a temática e legislação ambiental. A temática pode envolver conhecimento sobre programas, bem como normativos que regem sobre o território nacional, assim como sobre o Estado e a Instituição pesquisada.

A maioria dos participantes consideram ter um "bom" (74,19\%) conhecimento sobre temática e legislação. Considera-se como temática e legislação ambiental, algumas que estão relacionados a normativas, como o art. 16, do Decreto no 7.746/2012 (Brasil, 2012), Instrução Normativa SLTI/MPOG no 10/2012 (Brasil, 2012), e Planos de Gestão de Logística Sustentável.

Os resultados mostram que há uma grande preocupação quanto ao "não" conhecimento dos servidores em relação a "existência da Comissão" e "suas atribuições dentro da Universidade", com $77,44 \%$ e $80,64 \%$ respectivamente. A comissão socioambiental da UFT foi criada com o intuito de "contribuir para a formação de um pensamento sustentável na UFT, bem como transmitir novos valores sustentáveis a toda comunidade acadêmica (servidores docentes e técnicos, além de alunos e colaboradores terceirizados) para além dos muros da Universidade" (UFT, 2018). Observar que a maioria dos servidores pesquisados não a conhece, bem como não tem conhecimento sobre suas atribuições, torna limitadora a visibilidade mesma dentro do âmbito da universidade.

Sobre autodeclaração dos servidores quanto ao conhecimento de normativos, existe outro fator limitador na Universidade Federal do Tocantins. Em análise, nos dados é possível notar que $38,70 \%$ dos servidores não conhecem nenhum normativo da Universidade ou que se sobreponha a ela, como o Plano Logístico Sustentável da Universidade. Após essa afirmação, observa-se uma maior limitação quanto a forma de conhecimento sobre normativos, como a Instrução Normativa SLT/MPOG no 10, de 12 de novembro de $2012(22,58 \%)$ na qual instrui sobre regras para elaboração dos Planos de Gestão de Logística Sustentável. Esses desafios são apontados pelos servidores no questionário aplicado, como um fator limitador, uma vez que são temas amplamente difundidos pelo Governos nas esferas da sociedade. Como destacado por Campagnin (2014) essa é uma premissa importante, uma vez que noções de sustentabilidade, como leis, decretos, redefinições do termo, relatórios de sustentabilidade, têm sido enfatizadas todos os anos, por governos, com objetivo de influenciar uma nova cultura de responsabilidade nos setores da sociedade.

\section{A comissão socioambiental e} sua relação com a Instituição

Quanto à percepção dos servidores quanto à comissão socioambiental e sua relação com a instituição, alguns apontamentos puderam ser avaliados. Os servidores destacaram que a Comissão deveria realizar levantamento na UFT para categorizar o funcionamento de aparelhos que provocam ruídos, bem como promover palestras com o público da UFT para conscientização sobre o tema. Foi possível destacar que existe um problema quanto a relação da comissão para com a instituição. Para isso, servidores destacam que a mesma deveria proceder com fiscalização das práticas dentro das devidas normativas e 
leis e que a proposta e missão da comissão deva ser apresentada à comunidade acadêmica com um todo, para que as práticas possam ser difundidas, pois pouco se sabe sobre essa comissão.

\section{A questão socioambiental e a institucionalização na UFT}

Nesta etapa do questionário, foi questionado aos servidores sobre a questão socioambiental e sua institucionalização na Universidade. Quando perguntados sobre a presença de algum "diagnóstico para a identificação dos prováveis impactos ambientais decorrentes das atividades da Universidade", 87,10\% dos participantes responderam que "não" conhecem nenhum objeto na UFT. Já sobre a "mensuração ou levantamento estatístico das práticas socioambientais", 90,32\% responderam que "não" conhecem. Para Martins (2015, p. 5) "o valor sinalizado por instrumentos econômicos de gestão emerge como uma unidade de mensuração dos prejuízos ambientais e do nível de escassez dos recursos naturais". 0 não conhecimento destes instrumentos pela maioria dos servidores, parte da concepção de duas respostas: não existem esses instrumentos; existem, mas não são levados ao conhecimento de todos no âmbito institucional.

Outra preocupação quanto a atuação da Comissão Socioambiental da UFT é a disponibilização de levantamentos estatísticos de práticas socioambientais, com $83,87 \%$ dos participantes "não" tendo conhecimento de tal prática. Essa questão em si justifica muito, sobre o fator limitante da Comissão Socioambiental da UFT sobre as práticas e divulgação de conhecimento e informação.

\section{Sensibilização e capacitação socioambiental na UFT \\ Essa parte dos dados buscou mostrar de que forma os servidores obtém conhecimentos referentes às práticas e normativos socioambientais fornecidos pela Comissão Socioambiental na UFT (Tabela 3).}

Tabela 3. Sensibilização e capacitação socioambiental na UFT.

\begin{tabular}{|c|c|}
\hline \multicolumn{2}{|c|}{ Meios pela qual é informado sobre normativos e práticas socioambientais } \\
\hline Não tem conhecimento & $41,93 \%$ \\
\hline PAD - Processo administrativo digital & $00,00 \%$ \\
\hline Comissão Socioambiental (pagina ou blog) & $00,00 \%$ \\
\hline Publicação no Boletim Interno & $6,45 \%$ \\
\hline Cursos e treinamentos & $12,90 \%$ \\
\hline Informações ou orientações em e-mail institucional & $38,70 \%$ \\
\hline \multicolumn{2}{|l|}{ Meios de sensibilização e capacitação socioambiental da comissão } \\
\hline Não sei informar & $48,38 \%$ \\
\hline Foruns e debates & $16,12 \%$ \\
\hline Orientações por email institucional & $19,67 \%$ \\
\hline Folders & $9,67 \%$ \\
\hline Cursos e treinamentos & $16,12 \%$ \\
\hline \multicolumn{2}{|c|}{$\begin{array}{l}\text { Ações e Informações da Comissão Socioambiental - As ações e informações disponibilizada } \\
\text { pela comissão socioambiental são suficientes e eficazes para a incorporação de práticas? }\end{array}$} \\
\hline Sim & $00,00 \%$ \\
\hline Não & $16,12 \%$ \\
\hline Precisa melhorar & $74,19 \%$ \\
\hline Não sei opinar & $9,67 \%$ \\
\hline
\end{tabular}


Tabela 3. Continuação.

\begin{tabular}{l|c}
\hline Sim & $0,00 \%$ \\
\hline Não & $32,25 \%$ \\
\hline Parcialmente & $58,06 \%$ \\
\hline Não conheço & $9,67 \%$ \\
\hline
\end{tabular}

Sobre os meios pela qual é informado sobre normativos e práticas socioambientais - a maioria dos servidores "não tem conhecimento" sobre nenhuma prática de disseminação sobre normativos e práticas socioambientais na Universidade. Os números vêm corroborando uma premissa preocupante, quanto aos meios da chegada de informações aos servidores da universidade. Destaca-se que a maior forma de disseminação de informações sobre normativos e práticas socioambientais da Universidade é levada por email $(38,70 \%)$, e com pouca adequação para "cursos e treinamentos".

Sobre os meios de sensibilização e capacitação socioambiental da comissão nota-se que $48,38 \%$ dos participantes da pesquisa não souberam informar sobre os meios de sensibilização e capacitação da comissão. Sobre a eficiência dessas ações e informações

$\mathrm{Na}$ linha de ações e Informações da Comissão Socioambiental foi usado para se avaliar o índice de adesão de práticas socioambientais, por parte dos agentes da universidade é necessário que se conheça sobre as ações e informações que são disponibilizadas pela Comissão Socioambiental para entender se estão sendo corretamente influenciados. Dessa forma, percebe-se que os servidores sentem necessidade dessas ações e informações, quando 74,19\% afirmam que as ações e informações "precisa melhorar". Sobre a sensibilização e orientação nota-se que $58,06 \%$ dos participantes recebem sensibilização e orientação parcial, enquanto 32,25\% afirmam não receber de forma alguma.

\section{Práticas socioambientais}

Constata-se nos resultados que $41,93 \%$ dos pesquisados apontaram que "não" conhece ações e práticas socioambientais nas UFT. 35,49\% afirmam que "sim" conhecem algumas ações e práticas socioambientais e $22,58 \%$ afirmam que "não sabem responder" sobre a ocorrência dessas ações e práticas. Contudo há de se estabelecer que práticas e ações no âmbito público tem um fator limitador muito importante que pode dificultar a implantação das mesmas: o baixo investimento. Para Almeida (2015) os baixos investimentos nas instituições, assim como a falta de apoio, por meio de demandas e providências legais de financiamento para universidade pública, fazem com que as mesmas ofereçam modelos insustentáveis, com poucas ações significativas para instituição e consequentemente para o ambiente e sociedade. Ao saber, estabelece-se aqui o reconhecimento de que a implantação de práticas e ações são parcialmente influenciadas por outros fatores, como a falta de recurso.

Quanto frequência das ações e práticas desenvolvida na Universidade, $48,38 \%$ afirmam dos servidores afirmam que "nunca" acontecem, 25,80\% acontecem "esporadicamente"; $16,12 \%$ acontece "muitas vezes" e 9,67\% são ações e práticas de ordem "permanentemente". Os participantes da pesquisa também colocaram suas percepções quanto ao pressuposto de influência para adesão de práticas socioambientais dentro da universidade. 
Sobre Realização de práticas socioambientais, $25,81 \%$ dos servidores acreditam que a realização das mesmas dentro da Universidade "não acontece", e $51,61 \%$ das que acontecem advém do caráter voluntário dos agentes que pertencem à universidade, como servidores, alunos, terceirizados, requisitados, etc. Caso as práticas socioambientais na Universidade tivessem apenas caráter voluntário, os $73,50 \%$ servidores acredita que a ações ambientais continuariam sendo desenvolvidas. $\mathrm{Na}$ perspectiva Lima (2018) as instituições são importantes e fazem muito bem seu papel social, por meio das determinações legais ou até mesmo de forma voluntária, para resolução de problemas socioambientais.
Sobre os atores envolvidos efetivamente nas práticas socioambientais, os servidores que acreditam que a efetividade do desempenho das práticas é resultado da vontade de "todos" contam apenas 22,58\%, enquanto $41,93 \%$ partem dos servidores efetivos, $12,90 \%$ dos colaboradores e $6,45 \%$ dos estagiários e requisitados.

Também foram avaliados eixos sobre uso Racional de Recursos Naturais e Bens Públicos, dos quais se destacam o consumo de energia elétrica, o consumo de água, o consumo de papel, bem como o consumo de copos plásticos. Os resultados são provenientes da percepção dos servidores, quanto ao conhecimento da efetividade das práticas são mostrados na Tabela 4.

Tabela 4. Uso racional de recursos naturais e bens públicos.

\begin{tabular}{|c|c|c|c|c|}
\hline \multirow{3}{*}{ Especificação } & \multicolumn{4}{|c|}{ Efetividade da Prática na UFT } \\
\hline & \multicolumn{2}{|c|}{ Conhecida } & \multicolumn{2}{|c|}{ Implementada } \\
\hline & Sim & Não & Sim & Não \\
\hline \multicolumn{5}{|l|}{ Consumo de Energia Elétrica } \\
\hline Monitoramento da energia na unidade & $32,26 \%$ & $67,74 \%$ & $70,00 \%$ & $30,00 \%$ \\
\hline 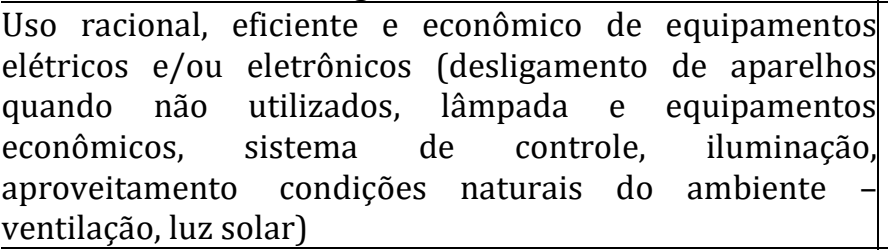 & $58,06 \%$ & $41,94 \%$ & $72,22 \%$ & $27,78 \%$ \\
\hline $\begin{array}{l}\text { Utilização de energia solar ou outra forma de energia } \\
\text { limpa }\end{array}$ & $35,48 \%$ & $64,52 \%$ & $54,45 \%$ & $45,45 \%$ \\
\hline \multicolumn{5}{|l|}{ Consumo de água } \\
\hline \begin{tabular}{|l|l} 
Monitoramento de consumo de água \\
\end{tabular} & $19,35 \%$ & $80,65 \%$ & $33,33 \%$ & $66,67 \%$ \\
\hline $\begin{array}{l}\text { Promoção de sensibilização de servidores e colaboradores } \\
\text { para o uso racional da água }\end{array}$ & $38,71 \%$ & $61,29 \%$ & $41,67 \%$ & 58,33 \\
\hline $\begin{array}{l}\text { Uso racional, eficiente e econômico da água (torneiras de } \\
\text { pressão, sensores para acionamento automático; inspeções } \\
\text { das instalações hidráulicas para detectar vazamentos e uso } \\
\text { inadequados dos recursos) }\end{array}$ & $22,58 \%$ & $77,42 \%$ & $71,43 \%$ & $28,57 \%$ \\
\hline $\begin{array}{l}\text { Implantação de sistemas de captação e aproveitamento de } \\
\text { água de chuva com utilização de água não potável em } \\
\text { sistemas sanitários, lavagens e irrigações externas }\end{array}$ & $16,13 \%$ & $83,87 \%$ & $60,00 \%$ & $40,00 \%$ \\
\hline \multicolumn{5}{|l|}{ Consumo de papel } \\
\hline $\begin{array}{llllll}\begin{array}{l}\text { Monitoramento de consumo de } \\
\text { impressão e cópias }\end{array} & & & & & \\
\end{array}$ & $22,58 \%$ & $77,42 \%$ & $71,43 \%$ & $28,57 \%$ \\
\hline Priorização da utilização papel reciclado e não clorado & $38,71 \%$ & $61,29 \%$ & $41,67 \%$ & $58,33 \%$ \\
\hline
\end{tabular}


Tabela 4. Continuação.

\begin{tabular}{|c|c|c|c|c|}
\hline \multirow{3}{*}{ Especificação } & \multicolumn{4}{|c|}{ Efetividade da Prática na UFT } \\
\hline & \multicolumn{2}{|c|}{ Conhecida } & \multicolumn{2}{|c|}{ Implementada } \\
\hline & Sim & Não & Sim & Não \\
\hline $\begin{array}{l}\text { Otimização de impressões e uso de papel (impressão } \\
\text { frente e verso ou múltiplas páginas por folha; manutenção } \\
\text { de impressoras; adoção do modelo de "ilhas de } \\
\text { impressão"; utilização de "fonte ecológica" em documentos } \\
\text { oficiais) }\end{array}$ & $32,26 \%$ & $67,74 \%$ & $60,00 \%$ & $40,00 \%$ \\
\hline $\begin{array}{l}\text { Utilização de sistemas informatizados, } \\
\text { eletrônicos digitais e de internet suprindo a necessidade } \\
\text { de impressão e utilização de papel }\end{array}$ & $48,39 \%$ & $51,61 \%$ & $31,59 \%$ & $68,42 \%$ \\
\hline \multicolumn{5}{|l|}{\begin{tabular}{|l|l|} 
Consumo de copos plásticos \\
\end{tabular}} \\
\hline $\begin{array}{l}\text { Promoção da conscientização para redução do uso de } \\
\text { copos descartáveis e substituição pelo uso de impressão e } \\
\text { utilização de papel }\end{array}$ & $61,29 \%$ & $38,71 \%$ & $31,58 \%$ & $68,42 \%$ \\
\hline $\begin{array}{l}\text { Disponibilização de copos permanentes para servidores e } \\
\text { colaboradores }\end{array}$ & $35,48 \%$ & $64,52 \%$ & $45,45 \%$ & $63,64 \%$ \\
\hline Monitoramento do consumo de copos plásticos & $45,16 \%$ & $54,84 \%$ & $35,71 \%$ & $64,29 \%$ \\
\hline
\end{tabular}

Nota: Os resultados de "sim" e "não" da coluna "implementada" são porcentagens equivalentes da coluna "sim" de "conhecida", não sendo considerado o percentual de "não" da coluna de "conhecida".

Os eixos conhecidos com maior taxa de implementação conhecida estão em "consumo de copos descartáveis", com porcentagens de 68,42\%,63,64\% e $64,29 \%$, respectivamente. No eixo, "consumo de água", observa-se menor conhecimento dos servidores quanto as práticas, sendo esse o resultado mais negativo, com $80,65 \%$ sobre "Monitoramento de consumo de água" 83,87\% sobre "Implantação de sistemas de captação e aproveitamento de água de chuva" e 77,42\% sobre "Uso racional, eficiente e econômico da água". Sousa, Sousa e Carvalho (2014) afirmam que as universidades causam grande degradação ambiental, uma vez que suas atividades acionam grandes impactos em seus espaços geográficos, o que reforça a tangibilidade de aplicar e desenvolver medidas que resolvam esses problemas de forma integralizada em torno dos agentes causadores.

Na Tabela 5 os resultados quanto a percepção dos servidores em relação a gestão adequada de resíduos gerados pela universidade. As práticas citadas são: coleta seletiva e; gestão de recursos perigosos.

Por meio dos dados, é possível notar que ambos os eixos de práticas ambientais são pouco conhecidos pelos servidores da universidade. Evidencia-se que no eixo de coleta seletiva, a "conscientização e sensibilização de servidores e colaboradores quanto à aplicação da Política dos 5R's" apresenta percentual de $74,19 \%$ de "não" conhecida e $75,00 \%$ de "não" implementada" por aqueles que conhecem.

No Eixo de práticas de "gestão de resíduos perigosos" destaca-se "utilização de logística reversa de resíduos perigosos" com $77,42 \%$ de "não" conhecido e $57,14 \%$ que afirmam que "não" é implementado por aqueles que conhecem. A "Reciclagem" é uma prática preocupante dentre todos as práticas dos resultados. Apresenta 70,97\% de "não" conhecimento por parte dos servidores e $77,78 \%$ não implementado por aqueles que conhecem. 
Tabela 5. Gestão adequada dos resíduos gerados.

\begin{tabular}{|c|c|c|c|c|}
\hline \multirow{2}{*}{ Especificação } & \multicolumn{2}{|c|}{ Conhecida } & \multicolumn{2}{|c|}{ Implementada } \\
\hline & Sim & Não & Sim & Não \\
\hline \multicolumn{5}{|l|}{ Coleta seletiva } \\
\hline $\begin{array}{l}\text { Reciclagem (de papel, papelão, plásticos, cartuchos de } \\
\text { toner) }\end{array}$ & $29,03 \%$ & $70,97 \%$ & $22,22 \%$ & $77,78 \%$ \\
\hline $\begin{array}{l}\text { Descarte e destinação corretos de materiais recicláveis e } \\
\text { não recicláveis }\end{array}$ & $35,48 \%$ & $64,52 \%$ & $36,36 \%$ & $63,64 \%$ \\
\hline $\begin{array}{l}\text { Destinação de material reciclável às cooperativas ou } \\
\text { associações de catadores cadastradas de } \\
\text { recicláveis (coleta seletiva solidária) }\end{array}$ & $32,26 \%$ & $67,74 \%$ & $30,00 \%$ & $70,00 \%$ \\
\hline $\begin{array}{l}\text { Separação adequada de resíduos gerados (papel, plástico, } \\
\text { vidro, metal, comum ou materiais recicláveis e não } \\
\text { recicláveis) }\end{array}$ & $45,16 \%$ & $54,84 \%$ & $42,86 \%$ & $57,14 \%$ \\
\hline $\begin{array}{l}\text { Conscientização e sensibilização de servidores e } \\
\text { colaboradores quanto à destinação de resíduos e aplicação } \\
\text { da Política dos 5R's (repensar, recusar, reduzir, reutilizar e } \\
\text { reciclar) }\end{array}$ & $25,81 \%$ & $74,19 \%$ & $25,00 \%$ & $75,00 \%$ \\
\hline \multicolumn{5}{|l|}{\begin{tabular}{|c|} 
Gestão de Resíduos perigosos \\
\end{tabular}} \\
\hline $\begin{array}{l}\text { Descarte adequado de resíduos perigosos (lâmpadas } \\
\text { fluorescentes, pilhas, baterias) }\end{array}$ & $32,26 \%$ & $67,74 \%$ & $40,00 \%$ & $60,00 \%$ \\
\hline $\begin{array}{l}\text { Utilização de logística reversa de resíduos perigosos } \\
\text { (lâmpadas, pilhas, baterias, cartuchos e toners não } \\
\text { recicláveis) }\end{array}$ & $22,58 \%$ & $77,42 \%$ & $28,57 \%$ & $57,14 \%$ \\
\hline Elaboração de plano de gestão de resíduos & $25,81 \%$ & $74,19 \%$ & $25,00 \%$ & $75,00 \%$ \\
\hline $\begin{array}{l}\text { Destinação adequada de lixo eletrônico (computadores, } \\
\text { telefones, aparelhos) }\end{array}$ & $35,48 \%$ & $64,52 \%$ & $45,45 \% \%$ & $54,55 \%$ \\
\hline
\end{tabular}

Nota. Os resultados de "sim" e "não" da coluna "implementada" são porcentagens equivalentes da coluna "sim" de "conhecida", não sendo considerado o percentual de "não" da coluna de "conhecida".

Para os problemas em destaque, faz-se a recomendação fiel utilização das práticas dentro das diretrizes da A3P. Carvalho e Souza (2013, p. 4) explicam que na A3P "os gestores públicos programam práticas sustentáveis em suas atividades, através da execução de ações baseadas nos eixos temáticos do programa, gerando economia através do menor custo benefício para a Administração Pública". Ademais, "as decisões tomadas dentro dessas organizações podem gerar impactos significativos sobre a sociedade e sobre o meio ambiente" (Macedo et al., 2013, p. 3).

Quanto aos principais fatores limitadores da implantação de práticas socioambientais na Universidade Federal do Tocantins, os servidores apontaram que A "falta de informação e ou esclarecimentos" foi a principal $(31,81 \%)$ dificuldade apontada pelos servidores pra implementação de práticas socioambientais na UFT, seguido por "ausência de fiscalização efetiva" (19,69\%). Ao saber, muitas dessas práticas não são efetivadas por gargalos, que são atrelados inclusive pela gestão que entre muitas delas, destacam-se: falta de fiscalização, falta de normas e regulamentos, desinteresse, burocrática, falta de informações e conhecimento. Outros fatores condicionantes, pode-se destacar a falta de recursos. Aos fatores limitadores, Almeida (2015) faz uma interessante contextualização quando afirma que os baixos investimentos nas 
instituições, assim como a falta de apoio, por meio de demandas e providências legais de financiamento para universidade pública, fazem com que ofereçam modelos insustentáveis.

Quando questionados sobre quais os instrumentos ou estratégias são importantes para a efetividade das práticas socioambientais na UFT, 32,25\% responderam "legislação e normas eficazes", 35,48\% "fiscalização e auditoria das práticas exigidas" e 32,25\% apostam na "Sensibilização do corpo funcional". Os participantes complementam que o estímulo a conscientização do pessoas que faz uso de recursos da universidade, ajuda economizar. Além disso complementam sobre o uso das normativas e leis, como o PGLS e a gestão de resíduos sólidos, por exemplo. Os participantes afirmam ainda que, deveria existir ou difundir o conhecimento sobre práticas mais comuns de modo a economizar os custos e gastos desnecessários da Universidade, como coleta seletiva, energia solar, com eficiência econômica e destinação correta de resíduos; construção de ciclovias, calçadas; gestão de resíduos laboratoriais, como baterias e computadores.

Questionados sobre as práticas socioambientais desenvolvidas na UFT, $64,51 \%$ afirmaram que podem impactar positivamente para além do âmbito institucional, com reflexos sociais, enquanto $35,48 \%$ afirmam que não é suficiente. Essa premissa trata-se de uma prerrogativa de responsabilidade socioambiental, na qual parte de organizações para com meio ambiente e sociedade. Nesse pressuposto, Cavalcante (2012) afirma que "a responsabilidade socioambiental é aquela que a empresa/órgão tem com a sociedade e com o meio ambiente, além das obrigações legais e econômicas". Todavia, é considerado que para implantação de práticas desse tipo, seja necessário grandes investimentos de ordem administrativa.

\section{Considerações finais}

0 presente estudo teve o objetivo de analisar a institucionalização da gestão sustentável na Universidade Federal do Tocantins. Ao tentar caracterizar os instrumentos de gestão sustentável da Universidade Federal do Tocantins, foi possível discorrer e entender no estudo documental e bibliográfico, sobre os normativos que permeiam a institucionalidade de gestão socioambiental no cenário nacional, como, A3P, contratações sustentáveis, art. 16, do Decreto no 7.746/2012 (Brasil, 2012), Instrução Normativa SLTI/MPOG no 10/2012 (Brasil, 2012), bem como instrumentos específicos da Universidade Federal do Tocantins, como o PGLSUFT, Resolução no 6/2018 e o Plano de Logística Sustentável (UFT, 2018).

Ao tentar identificar a percepção dos servidores sobre a institucionalização da gestão sustentável na Universidade Federal do Tocantins, foi possível identificar inúmeros fatores limitadores associados à gestão da Comissão Socioambiental da UFT. Avaliase que a falta de conhecimento por parte dos servidores sobre a existência da Comissão, em si, é um problema grave, que notoriamente foi possível destacar inúmeros outros problemas, como a falta de conhecimento de práticas socioambientais e falta de comunicação para eixos que entonam a sustentabilidade e a responsabilidade no âmbito universitário. A falta de conhecimento sobre a Comissão, destacado pelos servidores, certamente foi um ponto relevante identificado por essa pesquisa, levando a intepretação de que muitos dos limites da institucionalização das práticas da gestão socioambiental da UFT está relacionada a falta de comunicação e transparência das informações.

Em ressalva dos principais resultados obtidos, resta destacar que foi identificado algumas deficiências na 
gestão sustentável da UFT. De maneira geral, alguns dos pontos mais limitadores, que abrangem todos os objetivos desta pesquisa foram:

- Maioria dos servidores não conhece sobre nenhuma normativa socioambiental. E esse é um ponto que vai de encontro aos resultados da primeira seção, onde pelo menos $74,19 \%$, - $a$ priori-dos respondentes afirmam ter um bom conhecimento sobre a temática socioambiental.

- Os servidores pouco conhecem sobre a Comissão Socioambiental.

- Metade dos servidores se sentem pouco sensibilizados para contribuir com a gestão sustentável, bem como não tem conhecimento sobre meios de sensibilização e capacitação.

- A maioria dos servidores não conhece práticas diretas da Comissão Socioambiental.

- Maioria dos servidores acham que a maior dificuldade para implementação de práticas socioambientais é falta de informação e ou esclarecimentos, seguido por falta de investimentos.

A relevância que seguiu a linha da pesquisa sobre a institucionalização da gestão sustentável da UFT, permitiu uma análise de inúmeras contações que cria relação entre gestão e responsabilidade socioambiental e responsabilidade para com servidores e comissão socioambiental. 0 conjunto de resultados puderam ser naturalmente avaliados no contexto social e ambiental na administração pública, guiados pela forma de ampliar a estabilidade sustentável na comunidade a qual a universidade pertence. As análises do estudo puderam contribuir para o conhecimento do público da universidade, bem como para o meio científico, servido como base para pesquisas e até como fonte de análise para possíveis melhorias na gestão sustentável da UFT.

Para estudos futuros, sugere-se que pesquisas sejam voltadas para objetivos específicos, na exploração de todos os projetos da Comissão Socioambiental, tendo como base os normativos e instrumentos da gestão pública, com foco no planejamento, execução e monitoramento de atividades e práticas socioambientais dentro da Universidade Federal do Tocantins.

\section{Conflito de interesses}

As autoras declaram não haver conflito de interesses.

\section{Referências}

Almeida, F. C. Papel das instituições de educação superior na gestão voltada para a sustentabilidade: uma análise da Universidade Federal do Tocantins a partir do plano de gestão de logística sustentável. Palmas: Universidade Federal Do Tocantins, 2015. (Dissertação de mestrado).

Berté, R. Gestão socioambiental no Brasil. 1. ed. São Paulo: Saraiva, 2009.

Biderman, R.; Macedo, L. S. V.; Monzoni, M.; Mazon, R. (Org.). Guia de compras públicas sustentáveis. 2. ed. Brasília: Ministério do Meio Ambiente, 2008.

Benites, L. L. L.; Polo, E. F. A sustentabilidade como ferramenta estratégica empresarial: governança corporativa e aplicação do triple bottom line na Masisa. Revista de Administração da UFSM - REA, v. 6, edição especial, p. 827-841, 2013.

Bisognin Soares, A. C.; Lorenzi Junior, D.; Almeida, D. M.; Ibdaiwi, T. K. R.; Lopes, L. F. D.; Falkembach, G. F. A gestão socioambiental em pauta: a análise do caso de uma Rede de Supermercados da Região Central do RS. Revista de Administração da UFSM - REA, v. 7, p.113-126, 2014. https://doi.org/ $10.5902 / 1983465912308$

Brasil. Lei no 6.938, de 31 de agosto de 1981. Dispõe sobre a Política Nacional do Meio Ambiente, seus fins e mecanismos de 
formulação e aplicação, e dá outras providências. Disponível em: <http://www.planalto.gov.br/ccivil_03/Leis/ L6938.htm>. Acesso em: 02 jan. 2019.

Brasil. Lei no 10.032, de 23 de outubro de 2000. Autoriza o Poder Executivo a instituir a Fundação Universidade Federal do Tocantins. Disponível em: <http://www. planalto.gov.br/ccivil_03/leis/L10032.htm>. Acesso em: 24 fev. 2019.

Brasil. Lei no 13.005, de 25 de junho de 2014. Aprova o Plano Nacional de Educação e dá outras providências. Disponível em: <http://www.planalto.gov.br/ccivil_03/_ato2 011-2014/2014/lei/l13005.htm>. Acesso em: 24 fev. 2019.

Brasil. Decreto no 7.746, de 5 de junho de 2012. Regulamenta o art. $3^{\circ}$ da Lei $n^{\circ}$ 8.666, de 21 de junho de 1993, para estabelecer critérios e práticas para a promoção do desenvolvimento nacional sustentável nas contratações realizadas pela administração pública federal direta, autárquica e fundacional e pelas empresas estatais dependentes, e institui a Comissão Interministerial de Sustentabilidade na Administração Pública - CISAP. (Redação dada pelo Decreto no 9.178, de 2017). Disponível em: <http://www.planalto. gov.br/ccivil_03/_Ato2011-2014/2012/ Decreto/D7746.htm>. Acesso em: $24 \mathrm{fev}$. 2019.

Brasil. Instrução Normativa SLTI/MPOG no 10, de 12 de novembro de 2012. Estabelece regras para elaboração dos Planos de Gestão de Logística Sustentável de que trata o art. 16, do Decreto no 7.746, de 5 de junho de 2012, e dá outras providências. Disponível em: <https://www.comprasgovernamentais. gov.br/index.php/legislacao/instrucoesnormativas/394-instrucao-normativa-n-10de-12-de-novembro-de-2012>. Acesso em: 24 fev. 2019.

Cabral, E. R.; Gomes, S. C. Gestão ambiental pública em municípios com forte correlação entre desmatamento e expansão da pecuária, da soja e da madeira. Ensaios FEE, v. 34, n. 1, p. 167-194, 2013.

Carvalho, D. B.; Souza, E. S. Agenda ambiental da administração pública (A3P) e licitações: um estudo no restaurante universitário da universidade federal do Piauí. Anais do XIII Coloquio de Gestión Universitaria, Florianópolis, UFSC, 2013.
Carvalho, J. L. F.; Vergara, S. C. A fenomenologia e a pesquisa dos espaços de serviços. Revista de Administração de Empresas, v. 42, n. 3, p. 78-91, 2002. https://doi.org/10.1590/S0034-75902002 000300008

Cavalcante, M. L. S. A. Administração Pública e Agenda Ambiental - A3P - considerações sobre a implementação nos órgãos públicos. Revista Controle, v. 10, n. 1, p. 193-2016. Disponível em: <https://www.tce.ce.gov.br/ edicoes/revista-controle-volume-x-n-1-janjun-2012/send/176-revista-controlevolume-x-n-1-jan-jun-2012/1776-artigo-9administracao-publica-e-agenda-ambientala3p-consideracoes-sobre-a-implementacaonos-orgaos-publicos>. Acesso em: $28 \mathrm{dez}$. 2018.

Campagnin, L. Plano de gestão de logística sustentável: proposta de um modelo para avaliação do desempenho socioambiental em instituições da rede federal de educação profissional e tecnológica. Florianópolis: Universidade Federal de Santa Catarina, Centro Sócio-Econômico, 2014. (Dissertação de mestrado).

Cogo, G. A. R.; Oliveira, I. L.; Tesser, D. P. Agenda Ambiental na Administração Pública (A3P) - Um instrumento a favor da sustentabilidade na Administração Pública. Anais do XXXII Encontro Nacional de Engenharia de Produção, Bento Gonçalves, 2012.

Donaire, D. A repercussão da questão ambiental na organização. In: Donaire, D. Gestão ambiental na empresa. 2. ed. São Paulo: Atlas, 2010, p. 91-119.

Elkington, J. Cannibals with forks: The triple bottom line of 21 st century business. Oxford: Capstone, 1999.

Galvão, H. M. Influência da gestão socioambiental no desempenho da eco inovação empresarial. São Paulo: Universidade de São Paulo, Departamento de Administração, 2014. (Tese de doutorado).

Garcia, K. C.; Teixeira, M. G.; Alves, C. C.; Alves, R. N. Concepção de um modelo matemático de avaliação de projetos de responsabilidade social empresarial (RSE). Gestão \& Produção, v. 14, n. 3, p. 535-544, 2007. https://doi.org/10.1590/S0104-530X2007 000300009 
Huller, A. A educação ambiental em órgãos públicos municipais através da A3P (Agenda Ambiental na Administração Pública) como uma nova ferramenta de gestão. Revista Eletrônica do Mestrado em Educação Ambientiental, v. 25, p. 1517-1256, 2010. https://doi.org/10.14295/remea.v25i0.3522

Lima, N. B. Institucionalização da gestão sustentável no Tribunal de Justiça do Tocantins. Palmas: Universidade Federal do Tocantins, 2018. (Dissertação de mestrado).

Lopes, V. N.; Pacagnan, M. N. Marketing verde e práticas socioambientais nas indústrias do Paraná. Revista de Administração, v. 49, n. 1, p. 116-128, 2014. https://doi.org/ $10.5700 /$ rausp 1135

Louette, A. (Org.). Gestão do conhecimento: compêndio para a sustentabilidade ferramenta de gestão para a responsabilidade socioambiental. São Paulo: Antakarana Cultura Arte e Ciência, 2007.

Macedo, C. V. P.; Freitas, A. A. F.; Guerra, D. S. Uma escala para mensuração da importância percebida pelos docentes sobre a abordagem socioambiental nos cursos de administração de empresas. RAM, Revista de Administração Mackenzie, v. 14, n. 1, p. 7597, 2013. https://doi.org/10.1590/S167869712013000100004

Martins, R. C. A classificação disciplinar no mercado dos enunciados ambientais. Revista Brasileira de Ciências Sociais, v. 30, n. 87, p. 97-113, 2015. https://doi.org/10.17666/ 308797-113/2015

MMA - Ministério do Meio Ambiente. Responsabilidade social ambiental. 2019. Disponível em: <http://www.mma.gov.br/ responsabilidade-socioambiental/a3p>. Acesso em: 06 jan. 2019.

Nascimento, E. P. Trajetória da sustentabilidade: do ambiental ao social, do social ao econômico. Estudos Avançados, v. 26, n. 74 , p. 51-64, 2012. https://doi.org/ 10.1590/S0103-40142012000100005

Quintanda, C. G.; Quintanda, A. C.; Marca, L. S. Estratégias de sustentabilidade em gestão socioambiental: um estudo de caso em uma empresa do setor portuário. RIGC, v. 10, n. 19, 2012. Disponível em: <http://repositorio.furg.br/bitstream/handl e/1/5341/Estratégias de sustentabilidade em gestão socioambiental um estudo de caso em uma empresa do setor portuário.pdf>. Acesso em: 22 abr. 2019.

Rek, M. Gestão socioambiental na administração pública: uma análise do processo de institucionalização no Tribunal Regional Eleitoral do Paraná. Pato Branco: Universidade Tecnológica Federal do Paraná, 2017. (Dissertação de mestrado). Disponível em: <http://repositorio.utfpr.edu.br/jspui/ handle/1/2354>. Acesso em: 22 abr. 2019.

Santos, C. F. S. O.; Silva, M. E.; Gómez, C. R. P. Gestão estratégica da responsabilidade socioambiental empresarial: operacionalização por meio do sistema de gestão integrado. REGE - Revista de Gestão, v. 19, n. 4 , p. 535-552, 2012. https://doi.org/ $10.5700 /$ rege 477

Scandelari, V. R. N.; Cunha, J. C. Ambidestralidade e desempenho socioambiental de empresas do setor eletroeletrônico. Revista de Administração de Empresas, v. 53, n. 2, p. 183-198, 2013. https://doi.org/ 10.1590/S0034-75902013000200006

Scherer, F. L.; Gomes, C. M.; Madruga, L. R. G.; Crespam, C. C. Estratégia e práticas de gestão socioambiental: o caso das empresas brasileiras exportadoras do setor de calçados. Revista de Administração FACES Journal, v. 8, n. 4, p. 116-136, 2009.

Silva, G. S.; Almeida, L. A. Indicadores de sustentabilidade para instituições de ensino superior: uma proposta baseada na revisão de literatura. Revista de Gestão Ambiental e Sustentabilidade, v. 8, n. 1, p. 123-144, 2019.

Silva, G. S.; Almeida, L. A. Recomendações para a promoção de práticas sustentáveis na Universidade Federal do Tocantins, Campus de Araguaína. Revista Querubim, v. 3, p. 67125, 2019.

Souza, L. D.; Valadão Junior, V. M.; Medeiros, C. R. O. Crime corporativo e o discurso da responsabilidade socioambiental: inconsistências, contradições e indiferença no diálogo da corporação com stakeholders. Gestão \& Produção, v. 24, n. 4, p. 690-703, 2017. https://doi.org/10.1590/0104-530x1394-17

Tigre, P. B. Gestão da Inovação: a economia da tecnologia no Brasil. Rio de Janeiro: Elsevier, 2006. 
UFT - Universidade Federal do Tocantins. Plano Institucional da Universidade Federal do Tocantins (PDI-UFT) 20162020. Palmas: UFT, 2013. Disponível em: <https://ww2.uft.edu.br/index.php/pdi/pdi2016-2020>. Acesso em: 03 fev. 2019.

UFT - Universidade Federal do Tocantins. Sistema de Informações do Ensino (SIE). Palmas: UFT, 2018. Disponível em: <https://ww2.uft.edu.br/index.php/pdi/pdi2016-2020>. Acesso em: 06 fev. 2019.

Venturi, E. R. Cidadania empresarial: ferramentas de gestão e estudos empíricos sobre responsabilidade socioambiental. Revista Jurídica, v. 1, n. 38, p. 119-135, 2015. Disponível em: <http://revista.unicuritiba.edu.br/index.php /RevJur/article/view/1264/825>. Acesso em: 10. jan. 2019.

Viegas, S. F. S.; Cabral, E. R. Práticas de sustentabilidade em instituições de ensino superior: evidências de mudanças na gestão organizacional. Revista GUAL, v. 8, n. 1, p. 236-259, 2015.

Volpon, C. T.; Macedo-Soares, D. L. V. A. Alinhamento estratégico da responsabilidade socioambiental corporativa em empresas que atuam em redes de relacionamento: resultados de pesquisa na Petrobras. RAP, v. 41, n. p. 391-418, 2007.

Warken, I. L. M.; Henn, V. J.; Rosa, F. S. Gestão da sustentabilidade: um estudo sobre o nível de sustentabilidade socioambiental de uma instituição federal de ensino superior. Revista de Gestão, Finanças e
Contabilidade, Salvador, v. 4, n. 3, p. 147166, 2014.

Informação da Licença: Este é um artigo Open Access distribuído sob os termos da Licença Creative Commons Attribution, que permite uso irrestrito, distribuição e reprodução em qualquer meio, desde que a obra original seja devidamente citada. 